\title{
Spatial Variability and Temporal Trends of Climate Change in Southwest Ethiopia: Association with Farmers' Perception and Their Adaptation Strategies
}

\author{
Abera Habte $\mathbb{D}^{1},{ }^{1,2}$ Girma Mamo, ${ }^{3}$ Walelign Worku, ${ }^{1}$ Dereje Ayalew, ${ }^{4}$ \\ and Sebastian Gayler $\mathbb{D}^{5}$ \\ ${ }^{1}$ Hawassa University, Hawassa, Ethiopia \\ ${ }^{2}$ Wolaita Sodo University, Wolaita Sodo, Ethiopia \\ ${ }^{3}$ Ethiopian Institute of Agricultural Research, Addis Ababa, Ethiopia \\ ${ }^{4}$ Bahir Dar University, Bahir Dar, Ethiopia \\ ${ }^{5}$ Hohenheim University, Stuttgart, Germany \\ Correspondence should be addressed to Abera Habte; habteee@gmail.com
}

Received 14 April 2021; Revised 15 June 2021; Accepted 15 July 2021; Published 26 July 2021

Academic Editor: Julio Diaz

Copyright (C) 2021 Abera Habte et al. This is an open access article distributed under the Creative Commons Attribution License, which permits unrestricted use, distribution, and reproduction in any medium, provided the original work is properly cited.

The impact of climate change is a global threat, and its effect is more pronounced in developing countries. It is vital to link physical data analysis with endogenous knowledge and practices of farmers to strengthen their adaptive capacity. This study was conducted to explore spatial variability and temporal trends of temperature and rainfall in association with farmers' perceptions and their adaptation strategies in Southwest Ethiopia. Daily rainfall and temperature data of twelve weather stations were collected from the National Meteorological Agency of Ethiopia for the period 1983 to 2016. Farmers' perceptions about climate change and its impact and their adaptation strategies were assessed through a survey. Spatial variability and temporal trends of rainfall and temperature were analyzed using ArcGIS and R software. Sen's slope estimator and Mann-Kendall's trend tests were used to detect the magnitude and statistical significance of changes in rainfall and temperature. Spatial analysis of rainfall showed high variability over the region. There were no consistent and significant temporal trends of annual and seasonal rainfall of the area. Significant and upward trends of annual maximum and minimum temperatures were reported for all stations. Accordingly, annual maximum and minimum temperatures were increased by 0.71 and $0.65^{\circ} \mathrm{C}$, respectively, over the period 1983 to 2016 . Farmers had a good awareness of climate change and its impact. Adaptation strategies used by farmers included soil and water conservation practices $(66.21 \%)$, crop diversification $(62.16 \%)$, modifying planting date (42.56\%), agroforestry practices (35.13\%), use of drought-tolerant variety (33.95\%), use of early maturing crop (27.03\%), and livelihood diversification (25.42\%). As most of these adaptation strategies were familiarized by a small number of farmers, further effort is needed to identify factors limiting the adoption of these strategies. Furthermore, additional planned strategies and supports that widen available options at the farmers' disposal should be introduced to strengthen their adaptive capacity.

\section{Introduction}

Climate change is a global phenomenon, and its adverse effects challenge people's socioeconomic activities, health, livelihood, and food security [1]. The combined global land and ocean temperature showed a warming trend of $0.08^{\circ} \mathrm{C}$ per decade since 1880 and over twice that rate $\left(0.18^{\circ} \mathrm{C}\right)$ since 1981 [2]. For precipitation change, there is no consistent observed trend. Positive trends in some parts of the globe associated with an increasing number of heavy precipitation events as well as declining trends in other parts, giving strong indications for droughts, soil moisture stress, and other extreme events, have been reported [2]. Even though climate change is a global threat, developing countries are much more vulnerable than the industrialized world $[3,4]$, as they have much more limited human, institutional, and 
financial capacity to adapt to the associated challenges [5]. The case in Africa including Ethiopia is more pronounced than the global average particularly in more arid regions [2]. It is reported that Africa had already warmed by $0.7^{\circ} \mathrm{C}$ over the twentieth century [5]. In Africa, such changes bring a high burden on people whose livelihood is based on agriculture, which is mostly rainfed and highly vulnerable to the impact of climate change $[6,7]$.

Various pieces of evidence have been generated on trends of rainfall and annual minimum and maximum temperatures in Ethiopia. For instance, the National Meteorological Agency of Ethiopia (NMA) [8] reported that the annual minimum temperature had warmed by about $0.37^{\circ} \mathrm{C}$ over the period 1951 to 2006 . Likewise, the annual average maximum temperature showed an increasing trend of 0.2 to $0.28^{\circ} \mathrm{C}$ over the period 1960 to $2006[9,10]$. Similarly, Jury and Funk [11] reported an observed increasing trend in air temperature of $0.03^{\circ} \mathrm{C} /$ year for the period 1948 to 2006 . On the contrary, compiled evidence suggested that there is no consistent trend of rainfall over the country. Some parts of the country showed a declining trend [11-13] while others experienced an increasing trend [14-16] or no significant change [8, 17].

In Southern Ethiopia, varying pieces of evidence were generated on trends of temperature and rainfall change. For instance, Esayas et al. [18] reported an increase in maximum temperature by $0.64^{\circ} \mathrm{C}$ over the period 1983 to 2014 for the low land area of Southern Ethiopia. Similarly, significant increasing trends were observed for mean annual maximum and minimum temperatures of Jinka, while rainfall showed a nonsignificant upward trend for the last 30 to 40 years $[19,20]$. In addition, Araro et al. [16] reported mean annual minimum and maximum temperatures of the Konso district showing increasing trends. Other parts of the region have been experiencing similar trends for rainfall and temperature $[13,21,22]$.

Generating climate change information from the analysis of meteorological data without paying attention to local farmers' knowledge could limit the adoption and sustainability of various agricultural adaptation responses and may be leading to maladaptation $[23,24]$. On the other hand, farmers' perceptions may not always be in harmony with the reality and climate events or trends might be wrongly interpreted [25]. Therefore, comparing scientific evidence with farmers' perception of climate change and incorporating their indigenous knowledge into climate change adaptation strategies is a key to success [25-27]. In this context, three types of evidence have been generated in Ethiopia. First, observed changes in rainfall and temperature were described based on analysis of meteorological data that excludes knowledge of the local community [28, 29]. Second, the climate change was analyzed based on farmers' perceptions [30] alone, without triangulating with the information from physical data analysis. Third, other studies tide the meteorological data analysis with the local farmers' perception $[18,31]$, thus carrying richer information that helps in more informed decision making.

In the current study area, some pieces of evidence on the observed climate change have been generated from the analysis of metrological data [16, 19, 20, 22]. However, most of these studies generated only rainfall information for a small portion of the region. These studies have not also explored the spatial variability component and perceptions of farmers to climate change and their adaptation practices. Assessing existing changes in rainfall and temperature of an area through exploring the spatial variability and temporal trends and triangulating the evidence with farmers' perceptions on climate change and adaptation practices has paramount importance for exploring compatible adaptation strategies at the local level $[26,32]$. Therefore, this study was initiated to analyze the spatial variability and temporal trends of the climate elements involving temperature and rainfall and to scrutinize farmers' perceptions of climate change and their varying adaptation strategies in Southwest Ethiopia.

\section{Materials and Methods}

2.1. Description of the Study Area. The study was conducted in two administrative zones (South Omo and Segen Area People's Zones) of Southwest Ethiopia (Figure 1). South Omo Zone has an altitude ranging from 376 to 3500 m.a.s.l. and is located between $35^{\circ} 97^{\prime}-36^{\circ} 6^{\prime} \mathrm{E}$ and $4^{\circ} 43^{\prime}-6^{\circ} 46^{\prime} \mathrm{N}$. Similarly, Segen Area People's Zone has an altitude ranging from 501 to 3000 m.a.s.l. and is located between $37^{\circ} 1^{\prime}-38^{\circ} 01^{\prime} \mathrm{E}$ and $5^{\circ} 17^{\prime}-5^{\circ} 59^{\prime} \mathrm{N}$ [33]. The region has a mean annual rainfall of 435-1211 mm while annual maximum and minimum temperatures varied from 27.8 to 33.7 and $14.4-23.7^{\circ} \mathrm{C}$, respectively [34].

Agroecologically, most parts of the region are categorized into hot arid and semiarid while tropical subhumid climate is covering small areas [22, 33]. The region experienced bimodal rainfall, the first one occurring in Spring (from March to May) and the second in Autumn (from September to November).

\subsection{Data Source}

2.2.1. Observed Climate Data and Quality Control. Twelve meteorological stations from Southwest Ethiopia (South Omo and Segen Area People's Zones) such as Jinka, Gazer, Keyafer, Konso, Gidole, Gato, Arfide, Erbore, Demeka, Omorate, Beto, and Basketo were selected for observed climate change analyses (Figure 2). According to the NMA, most of these stations are class D recording only rainfall with a higher number of missing values. This data problem was resolved by NMA using a synthesis (gap filling) with ENACT gridded data set $(4 \mathrm{~km}$ by $4 \mathrm{~km}$ spatial resolution). This data set is a combination of ground-based observations managed by NMA and satellite estimates of rainfall and temperature from the European Organization for the Exploitation of Meteorological Satellites (EUMETSAT) and the US National Aeronautics and Space Administration (NASA) [18, 35]. The reconstruction of data was performed by the NMA in collaboration with International Research Institute for Climate and Society at Columbia University, USA, whereas data calibration and validation were carried out by Reading University, UK [18]. 


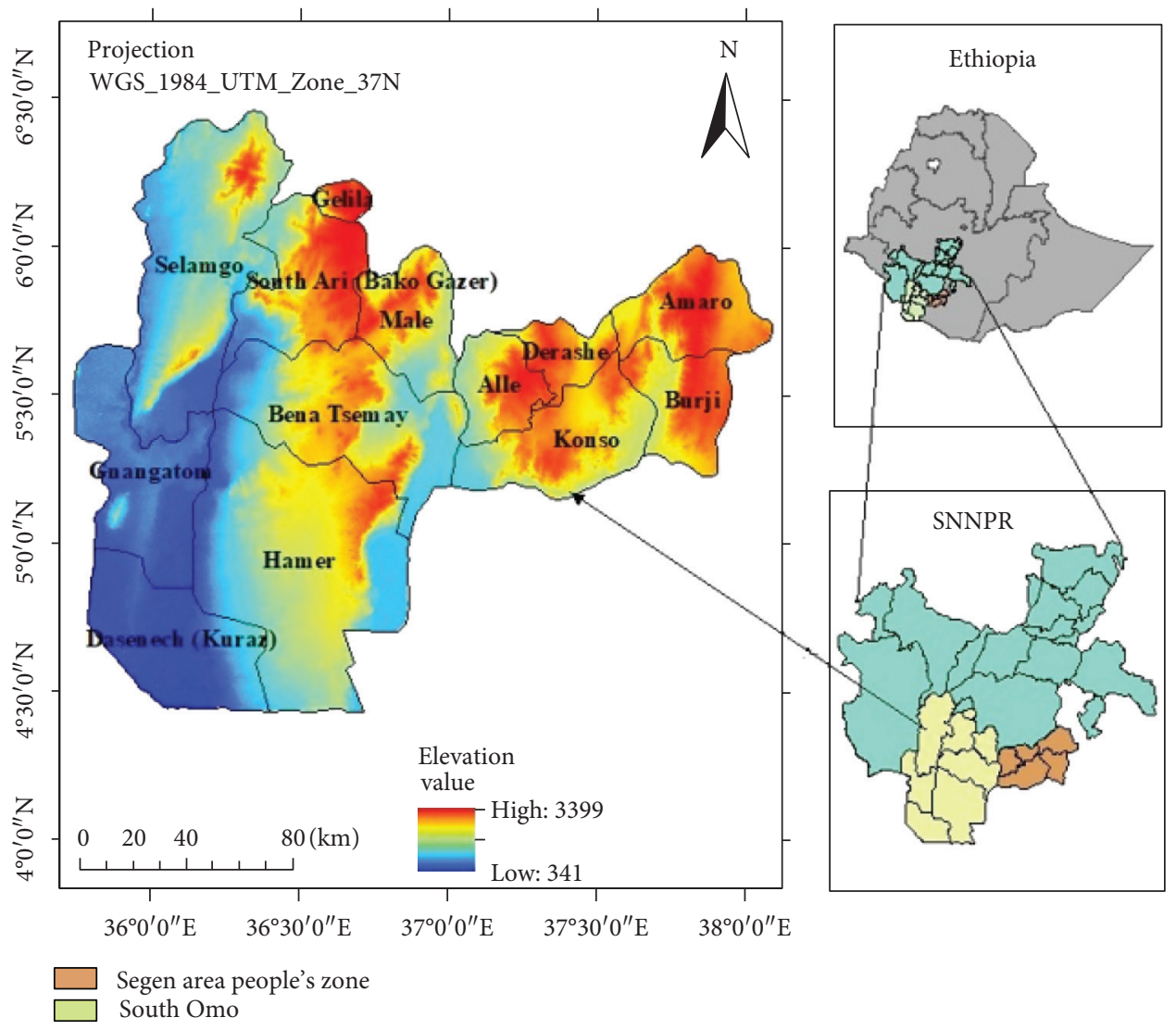

Figure 1: Map of the study area.

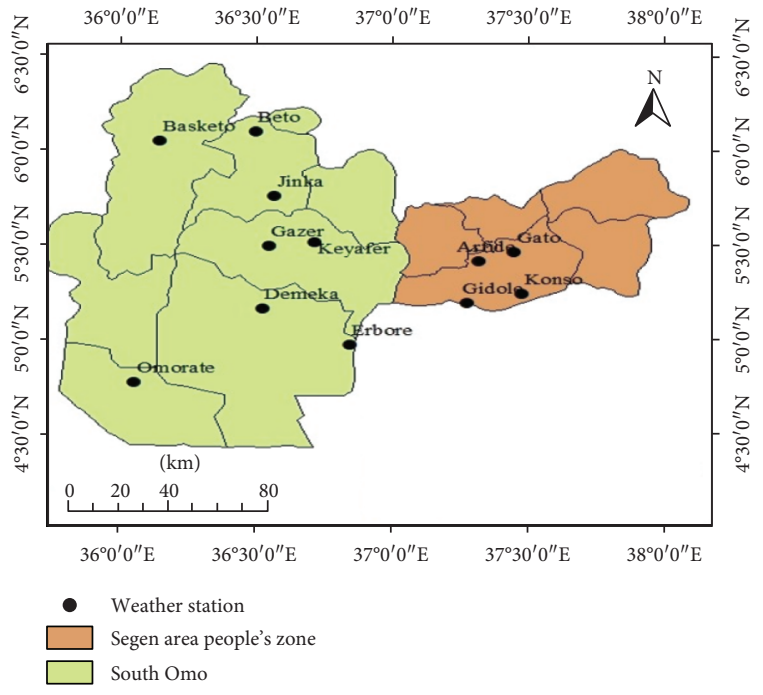

Figure 2: Spatial distribution of weather stations found in the study area.

Hence, using this data source, daily rainfall and daily maximum and minimum temperatures of the aforementioned stations for the period 1983 to 2016 were used for this study. Data quality control (homogeneity test, detecting the presence of outliers, values of maximum temperature lower than minimum temperature) was done using Rclimdex software in the R software program [36].
2.2.2. Survey Data Collection. Farm-level perceptions on climate change and its impact and adaptation strategies were explored using the survey to link farmers' knowledge with the result of climate data analysis. Household heads were selected using multistage sampling techniques in Southwest Ethiopia. First, South Omo and Segen Area People's Zones were selected purposively since they are leading sorghumproducing areas in Southern Ethiopia. Similarly, South Ari district from South Omo zone and Konso district from Segen area people zone and two kebeles (the smallest administrative units in Ethiopia) from each district were selected randomly. The total number of household heads in four selected kebeles was 3055 (1534 and 1521 from South Ari and Konso, respectively). Based on the following sample size determination formula [37], the total sample size of 4 kebeles was 354 .

$$
n=\frac{N}{1+N(e)^{2}},
$$

where $n$ is the sample size, $N$ is the population size (3055), and $e$ is the desired level of precision (0.05).

However, due to the scattered settlement of the population and harsh environmental conditions, the total sample size was reduced to 245 . By using the list of household heads from each district agricultural office, a total of 245 farm household heads were sampled randomly using probability proportional to the size (PPS) of the total households of each kebele. The household heads whose age 
was greater than 40 (age group having long-term observation on climate change) were screened before sampling. Interview, focus group discussion (FGDs), and key informant interview (KII) were used to collect data during the survey. A semistructured questionnaire was used during the interview to gather information on climate change and its impact and current adaptation measures undertaken. Focus group discussion and KII in each district were conducted to cross-check the information collected during the interview and compare it with climate data analysis.

\subsection{Data Analyses}

2.3.1. Spatial Variability of Rainfall and Temperature. The mean annual maximum and minimum temperature and annual and seasonal rainfall were interpolated between the selected weather stations to understand the spatial variability of precipitation and temperature, averaged over the period 1983 to 2016. Inverse Distance Weighting technique was employed for the interpolation using ArcGIS 10.4. This method was used in previous studies for a similar analysis $[15,17]$. The technique assumes that the interpolated surfaces (points) are most influenced by observations at nearby points and are less influenced by observation points with greater distance [38]. The coefficient of variation (CV) was computed to evaluate the spatial variability of mean annual and seasonal rainfall and the annual maximum and minimum temperatures of the stations across the region. Coefficients of variation less than $20 \%$, between 20 and $30 \%$, and higher than $30 \%$ indicate lower, moderate, and higher variability, respectively [39]. It is computed as

$$
\mathrm{CV}=\frac{\sigma}{\mu} \times 100
$$

where $\sigma$ is standard deviation and $\mu$ is the mean value of precipitation or temperature at annual or seasonal scale.

\subsubsection{Temporal Trend Analyses of Rainfall and Temperature}

(1) Serial Correlation. Before trend analysis, the serial correlation test for the time series data (1983 to 2016) was employed to avoid the effect of autocorrelation through checking the independence of observation from one year to the next [40]. Autocorrelation function (ACF package) [41] at lag 1 was used to check the presence of a significant autocorrelation using packages developed for $\mathrm{R}$ software. Lag 1 ACFs were computed using the following formula:

$$
r_{1}=\frac{\left(1 / n-1 \sum_{i=1}^{n-1}\left(X_{i}-\bar{X}\right)\left(X_{i+1}-\bar{X}\right)\right)}{1 / n \sum_{i=1}^{n}\left(X_{i}-\bar{X}\right)^{2}},
$$

where $r_{1}, X_{i}$, and $X$ are the correlation coefficient at lag 1 , rainfall (or temperature) time series, and mean value of the rainfall (or temperature) time series, respectively. The confidence interval of $r_{1}$ at the $5 \%$ significance level was computed as

$$
r_{1}(5 \%)=\frac{-1 \pm 1.96 \sqrt{n-1}}{n-1},
$$

where $n$ is the number of observations in the time series.

When $r_{1}$ falls within the confidence limits, a significant autocorrelation does not exist and the trend is examined using the Mann-Kendall (MK) trend test. On the other hand, if $r_{1}$ is found outside of the confidence interval, it indicates the presence of correlation between adjusted observations and the modified Mann-Kendall (MMK) test should be employed to remove the impact of autocorrelation [42]. In this study, both MK and MMK were used when there was independence and serial correlation, respectively, on time series analysis of rainfall and temperature using $\mathrm{R}$ software programs [43].

(2) Temporal Trend Analyses. The trend of rainfall was examined on an annual and seasonal basis while the temperature was looked at on an annual basis. Mann-Kendall's test [44, 45] and Sen's slope estimates [46], which are nonparametric methods for trend analysis, were used to examine the existence of temporal trends of rainfall and temperature. The MK test uses the correlation between the ranks of a time series and their sequence. It computes the difference between the later measured values and all early measured values for a time series of interest over time. When a data value from a later time period is higher than a data value from an earlier time period, the MK test statistic $S$ is incremented by 1 . On the other hand, if the data value from a later time period is lower than a data value sampled earlier, $S$ is decremented by 1 . The summation of each case gives the final value of $S$ using the following formula:

$$
S=\sum_{i=1}^{N-1} \sum_{J=i+1}^{N} \operatorname{sgn}\left(x_{j}-x_{i}\right)
$$

where $S$ is Mann-Kendall's test statistics, $x_{i}$ and $x_{j}$ are the sequential data values of the time series in the years $i$ and $j$ $(j>i)$, and $N$ is the length of the time series. A positive $S$ value indicates an increasing trend and a negative value indicates a decreasing trend in the data series.

The sign function, which was used to differentiate the types of trend, is given as

$$
\begin{aligned}
& +1, \quad \text { if }\left(X_{j}-X_{i}\right)>0, \\
& \operatorname{sgn}\left(x_{-} j-x_{-} i\right)=\left(0, \quad \text { if }\left(X_{j}-X_{i}\right)=0\right. \text {, } \\
& -1, \quad \text { if }\left(X_{j}-X_{i}\right)<0 .
\end{aligned}
$$

For samples, $n \geq 10$, the $S$ statistic is approximately normally distributed and the mean of $S$ is zero and the variance of $S$ is given as follows [47]:

$$
\sigma^{2}=\frac{1}{n}\left[n(n-1)(2 n+5)-\sum_{i=1}^{m}\left(t_{i}-1\right)\left(2 t_{i}+5\right)\right],
$$

where $n$ is the number of observations in the time series, $m$ is the number of tied groups, and $t_{i}$ is the number of observations in the $i^{\text {th }}$ group. 
The significance of a trend is computed by the $Z$ score using the following formula:

$$
Z= \begin{cases}\frac{S-1}{\sigma}, & \text { if } S>0, \\ 0, & \text { if } S>0, \\ \frac{S+1}{\sigma}, & \text { if } S>0 .\end{cases}
$$

The hypothesis that there is no trend is rejected when the $Z$ value is greater in absolute value than the critical value $Z \alpha$, at a chosen level of significance, $\alpha$.

Sen's Estimator of Slope. In addition to identifying the existence of a trend, the magnitude of a trend was estimated by a slope estimator $(\beta)$ which is applied in cases where the trend is assumed to be linear, depicting the quantification of changes per unit time. This method could be used with missing data and remain unaffected by outliers or gross errors [48]. The slope (change per unit time) was estimated following the procedure of Sen [46]. Sen's slope $(\beta)$ corresponds to the calculation of the median of the slopes on each pair of points in the time series where each measurement is performed at regular intervals. It was calculated as follows [44]:

$$
\beta=\operatorname{median} \frac{X_{i}-X_{j}}{i-j},
$$

where $X_{i}$ and $X_{j}$ are data values at time $t_{i}$ and $t_{j}(i>j)$, respectively. A positive value of $\beta$ indicates an "upward trend" (increasing values with time), while a negative value of $\beta$ indicates a "downward trend" [4].

2.3.3. Survey Data Analyses. Descriptive statistics such as the chi-square test and percentages were employed to summarize farmers' perceptions on climate change and its impact and adaptation strategies. Qualitative data obtained from focus group discussion and key informant interviews were summarized according to key themes and interpreted through concepts. Additional information on the sociodemography of the household head who participated in the interview is presented in the Supplementary Materials section (see S1-Table 1).

\section{Results}

3.1. Spatial Distribution and Variability of Rainfall and Temperature. Spatial distributions of long-term (1983 to 2016) mean annual rainfall showed the occurrence of higher rainfall in the northern parts compared to southern parts of the region with spatial variability of $37 \%$ (Figure 3 ). The highest mean annual rainfall $(1211.35 \mathrm{~mm})$ was observed at Basketo while the lowest value $(434.5 \mathrm{~mm})$ was observed at Erbore in South Omo which accounted for $36 \%$ of the maximum rainfall (Figure 3). Similar trends were observed for Spring (March, April, May), Summer (June, July, August), and Autumn (September, October, November) rainfall (Figure 3). On the contrary, the southern parts of the region experienced higher average annual maximum and minimum temperatures than the rest parts of the region (Figure 4). The average maximum annual temperature ranged from 27.8 to $33.7^{\circ} \mathrm{C}$ with spatial variability of $6.3 \%$, while the minimum temperature ranged from 14.4 to $23.7^{\circ} \mathrm{C}$ with spatial variability of $15.1 \%$.

\subsection{Temporal Trends of Changes on Temperature and Rainfall.} Serial Autocorrelation. The presence of autocorrelation for annual rainfall of Arfide meteorology station was observed (Figure 5(a)). On the contrary, Figure 5(b) shows the absence of association between the time series data of annual maximum temperature of the same station. Similarly, the autocorrelation function analysis for maximum and minimum temperature and annual and seasonal rainfall of the remaining meteorological stations showed similar trends (data not shown).

\subsubsection{Temporal Trends of Annual and Seasonal Rainfall.} Trend analysis of annual rainfall indicated that some parts of the region, mostly the southern parts with weather stations such as Arfide, Demeka, Gato, Jinka, and Omorate, experienced increasing trends ranging from 0.57 to $3.85 \mathrm{~mm} /$ year with an average value of $0.75 \mathrm{~mm} /$ year (Table 1). For instance, the annual rainfall of Arfide showed an increasing trend of $3.85 \mathrm{~mm} /$ year over the period 1983 to 2016 which implied an increment of $130.9 \mathrm{~mm}$ over this period. On the other hand, the remaining parts of the region with weather stations such as Gidole, Keyafer, Gazer, Konso, Basketo, Beto, and Erbore showed decreasing trends ranging from 0.5 to $2.77 \mathrm{~mm}$ /year with an average value of $0.23 \mathrm{~mm} /$ year (Table 1).

Most parts of the region showed decreasing trends of Belg rainfall ranging from 0.62 to $2.56 \mathrm{~mm} / \mathrm{season}$ with an average value of $2.08 \mathrm{~mm} /$ year while some parts of the region involving weather stations such as Arfide, Jinka, Basketo, and Beto experienced increasing trends ranging from 0.64 to $2.21 \mathrm{~mm}$ /year over the period 1983 to 2016 (Table 1). For both annual and Belg rainfall, the trends were statistically significant only for Gidole and Erbore, respectively (Table 1).

All parts of the region showed increasing trends of Autumn rainfall ranging from 0.21 to $5.87 \mathrm{~mm}$ /year with an average value of $2.5 \mathrm{~mm} /$ year (Table 2). However, the increment of Autumn rainfall was statistically significant for Arfide, Gazer, Jinka, Konso, and Omorate only. Decreasing trends of Kiremt rainfall were observed on most parts of the region ranging from 0.8 to $2.87 \mathrm{~mm} /$ year with an average value of $2.9 \mathrm{~mm} /$ year while Arfide, Gato, Jinka, and Omorate showed increasing trends with magnitudes ranging from 0.11 to $1.25 \mathrm{~mm} /$ year with an average value of $0.58 \mathrm{~mm} /$ year. However, both the increasing and decreasing trends were nonsignificant (Table 2).

\subsubsection{Temporal Trends of Annual Maximum and Minimum} Temperature. All parts of Southwest Ethiopia experienced increasing trends of annual maximum and minimum 


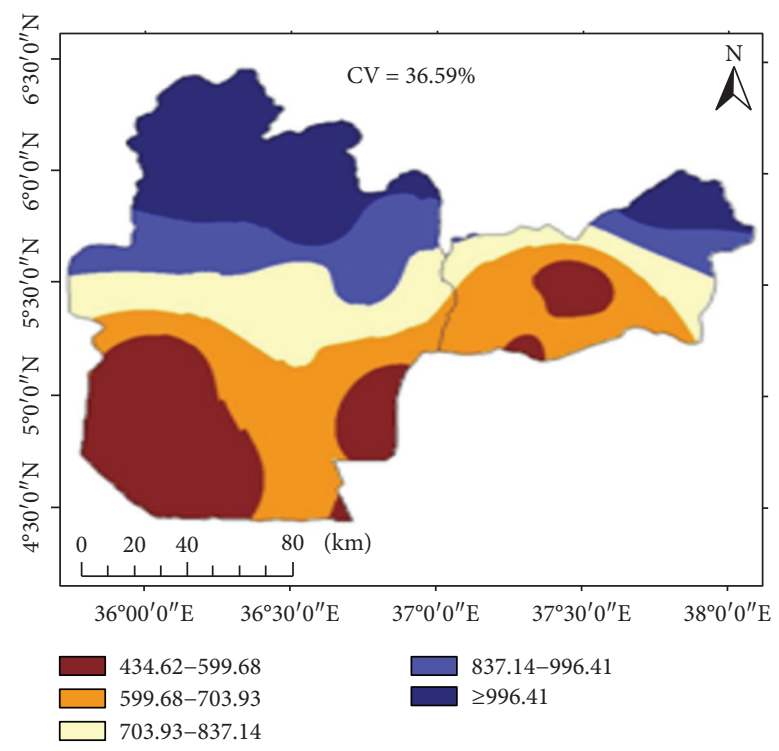

(a)

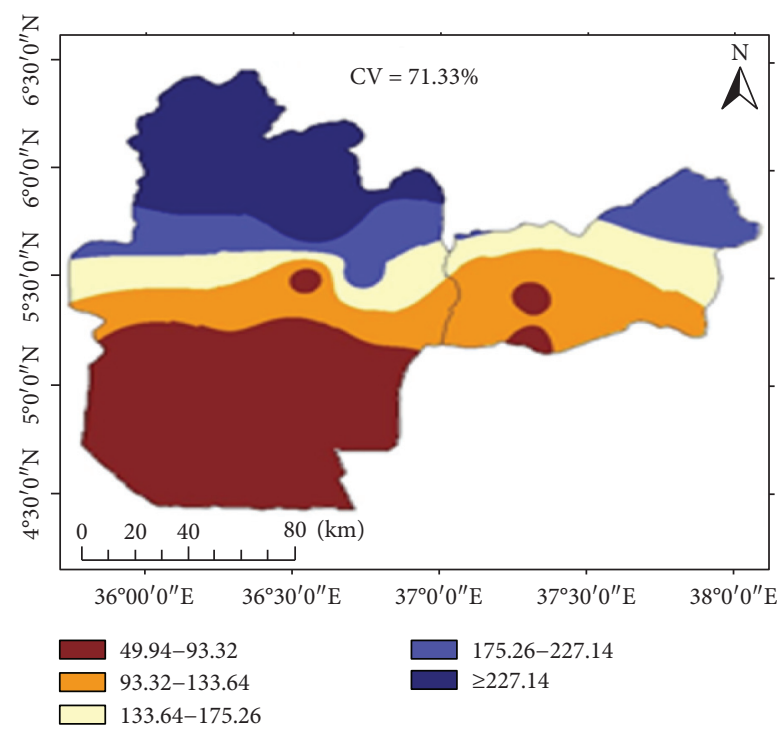

(c)

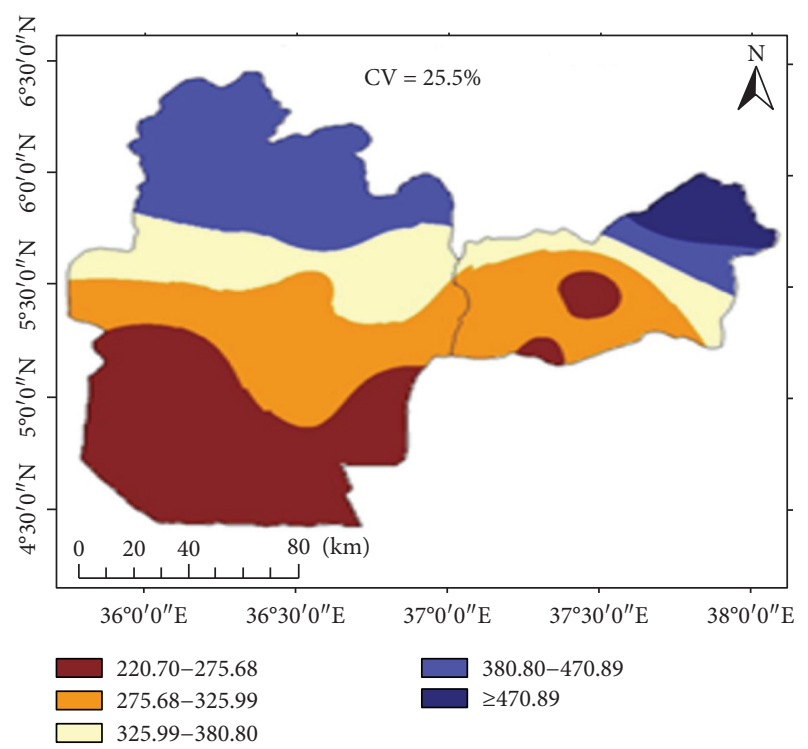

(b)

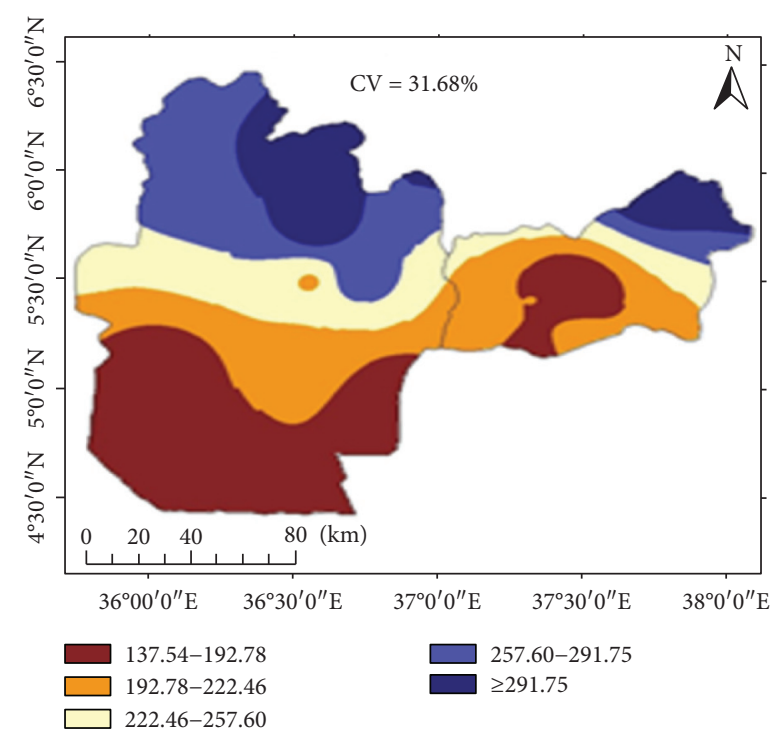

(d)

FIgURe 3: Spatial distribution and variability of mean annual and seasonal rainfall of Southwest Ethiopia (1983-2016). (a) Annual rainfall, (b) Spring (Belge) rainfall, (c) Summer (Kiremt) rainfall, and (d) Autumn rainfall.

temperatures for the period 1983 to 2016 (Table 3). Statistically significant trends for annual maximum and minimum temperature were observed for all stations except Erbore and Demeka, respectively (Table 3 ). The increasing trends of annual maximum temperature ranged from 0.008 to $0.041^{\circ} \mathrm{C} /$ year with a mean value of $0.021^{\circ} \mathrm{C} /$ year while trends of minimum temperature varied from 0.0015 to $0.037^{\circ} \mathrm{C} /$ year with an average value of $0.019^{\circ} \mathrm{C} /$ year (Table 3 ). This indicated that for the last 34 years, the annual maximum and minimum temperatures of the region were increased by 0.71 and $0.65^{\circ} \mathrm{C}$, respectively. The highest changes in annual maximum and minimum temperatures were observed at Gidole and Gazer with magnitudes of 0.041 and $0.037^{\circ} \mathrm{C} /$ year, respectively. Similarly, the lowest changes in annual maximum and minimum temperature were observed at
Keyafer and Demeka with magnitudes of 0.008 and $0.0015^{\circ} \mathrm{C} /$ year, respectively.

3.3. Farmers' Perception of Climate Change and Its Impact. The perception of farmers on climate change is presented in Table 4. The majority of the respondents in South Ari (94.11\%) and Konso (95.0\%) stated that they have the awareness of changes in the climate of their locality. In addition, there was no statistically significant $(P<0.05)$ difference between farmers in South Ari and Konso on their perception of climate change (Table 4 ). The Belg rainfall was considered in a declining front over the past three decades by 82 and $88 \%$ of the respondent farmers in South Ari and Konso, respectively (Table 4). However, 5.88 and $10.0 \%$ of 


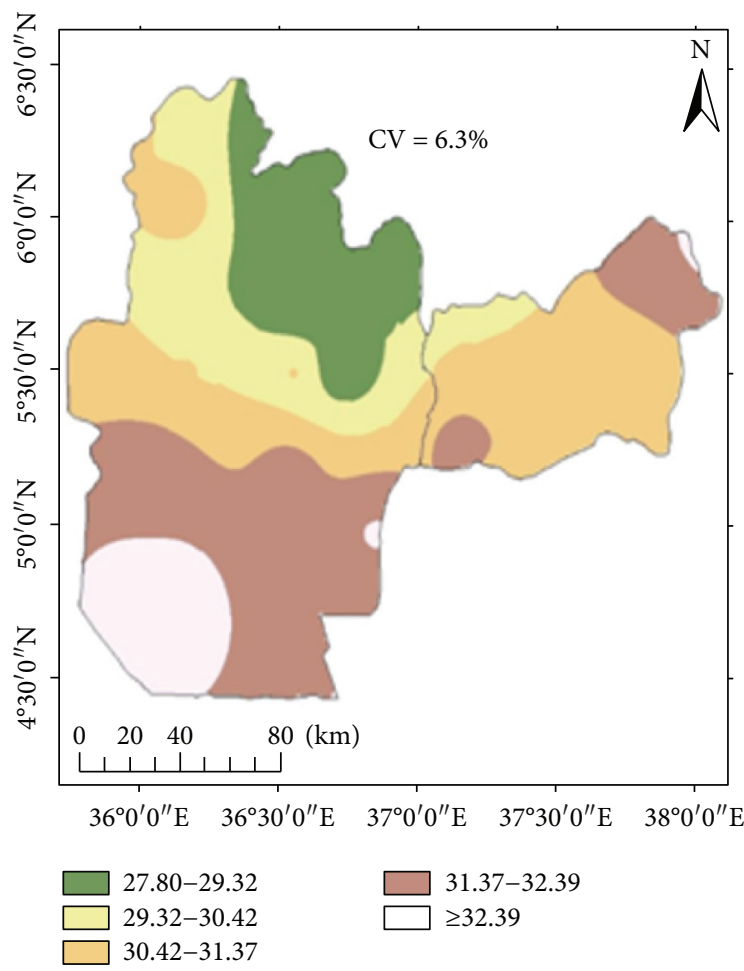

(a)

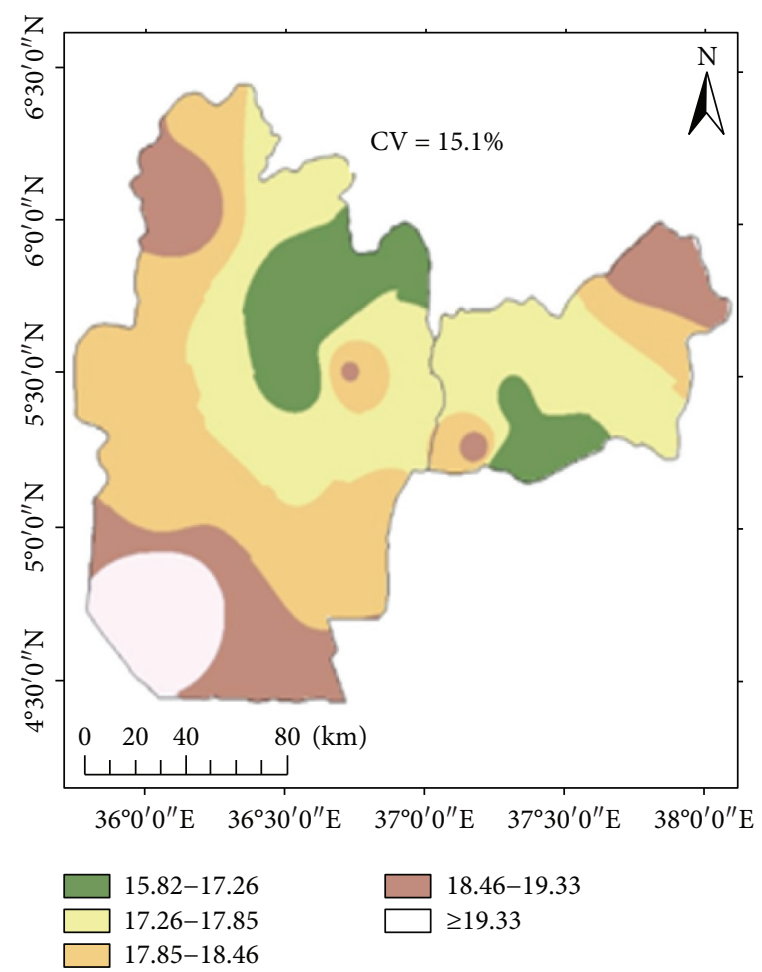

(b)

FIGURE 4: Spatial distribution and variability of mean annual maximum and minimum temperature of Southwest Ethiopia (1983-2016). (a) Annual maximum temperature $\left({ }^{\circ} \mathrm{C}\right)$. (b) Annual minimum temperature $\left({ }^{\circ} \mathrm{C}\right)$.

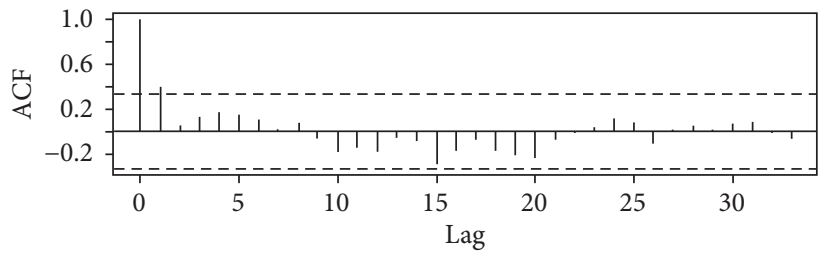

(a)

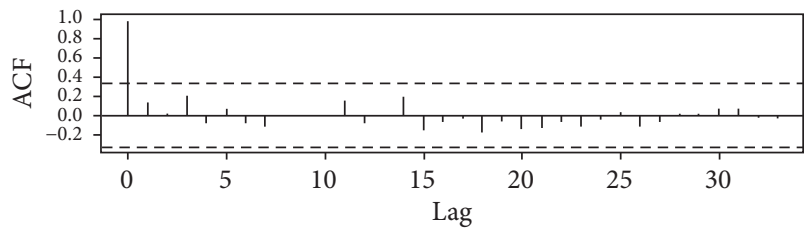

(b)

Figure 5: Autocorrelation of long-term areal annual rainfall and maximum temperature of Arfide, South Omo Ethiopia (period: 1983-2016). ACF = autocorrelation function; Lag = number of years considered during the time series analysis. (a) Annual rainfall. (b) Annual maximum rainfall.

the respondent farmers considered that the Belg rainfall increased for the same period. Similarly, the majority of the respondent farmers in South Ari (94.1\%) and Konso (82.5\%) considered that the Autumn rainfall decreased over the past thirty years. Regarding temperature, it was perceived as increased by 85.29 and $95 \%$ of the respondent farmers at South Ari and Konso, respectively (Table 4). The perceptions of farmers on changes in Belg and Autumn rainfall and temperature were not statistically different $(P<0.05)$ between the two locations.

The impacts of climate change were well recognized by the respondent farmers in the region (Figure 6). The decline in crop productivity (86.49\%), increased livestock disease $(74.32 \%)$, increased human disease $(60.81 \%)$, and increased drought frequency $(52.7 \%)$ were the major threats of climate change identified by the participant farmers. In addition, increased crop pest (48.3), water shortage for human and livestock use (43.24\%), and increased flood frequency (35.14) were other impacts of climate change perceived by the farmers with decreasing rank of severity.

Similarly, farmers who participated in the focus group discussion explained their perception of climate change and the risks they faced as follows.

The amount of rainfall we got during the crop growing period was decreased and our area becomes warmed as compared to the earlier period. Productivity of our crop and livestock was becoming lower and lower due to a shortage of water. Sometimes, we faced total failure of crop stand. 
TABLE 1: Trends of changes on annual and Belg rainfall of weather stations in Southwest Ethiopia for the period 1983-2016.

\begin{tabular}{|c|c|c|c|c|}
\hline \multirow{2}{*}{ Station name } & \multicolumn{2}{|c|}{ Annual RF } & \multicolumn{2}{|c|}{ Belg rainfall } \\
\hline & $\mathrm{Z}$ & Sens' slope & $\mathrm{Z}$ & Sens' slope \\
\hline Arfide & 1.38 & 3.85 & 0.64 & 0.64 \\
\hline Demeka & 0.59 & 2.0 & -0.76 & -1.5 \\
\hline Erbore & 1.17 & -2.77 & $-2.26^{*}$ & -4.4 \\
\hline Gato & 0.43 & 0.57 & -1.16 & -1.75 \\
\hline Gazer & -0.02 & -0.025 & -0.91 & -1.8 \\
\hline Gidole & $-0.67^{*}$ & -1.65 & -1.63 & -2.56 \\
\hline Jinka & 0.33 & 1.69 & 1.45 & 2.21 \\
\hline Keyafer & -0.21 & -1.15 & -1.44 & -2.53 \\
\hline Konso & -0.18 & -0.5 & -0.67 & -0.62 \\
\hline Omorate & 0.62 & 1.38 & -1.6 & -1.44 \\
\hline Basketo & -0.21 & -1.27 & -0.39 & -1.12 \\
\hline Beto & -0.11 & -0.69 & 0.83 & 2.07 \\
\hline
\end{tabular}

The symbol ${ }^{*}$ indicates a significant trend at $\alpha \leq 0.05$.

TABle 2: Trends of changes in Autumn and Kiremt rainfall of weather stations in Southwest Ethiopia for the period 1983-2016.

\begin{tabular}{lcccc}
\hline \multirow{2}{*}{ Station name } & \multicolumn{2}{c}{ Autumn } & \multicolumn{2}{c}{ Kiremt } \\
& $Z$ & Sens' slope & $Z$ & Sens' slope \\
\hline Arfide & $1.8^{*}$ & 3.6 & 1.26 & 0.79 \\
Demeka & 0.9 & 1.2 & -1.14 & -1.0 \\
Erbore & 0.25 & 0.32 & -1.47 & -0.8 \\
Gato & 1.70 & 1.25 & 1.09 & 0.167 \\
Gazer & $2.87^{* *}$ & 3.83 & -0.83 & -1.25 \\
Gidole & 1.58 & 2.0 & -1.72 & -1.5 \\
Jinka & $2.21^{*}$ & 5.87 & 0.83 & 1.25 \\
Keyafer & 0.03 & 0.21 & -1.69 & -2.87 \\
Konso & $2.41^{*}$ & 3.63 & -1.29 & -1.62 \\
Omorate & $2.72^{* *}$ & 3.25 & 0.15 & 0.111 \\
Basketo & 1.60 & 2.82 & -4.64 & -1.23 \\
Beto & 1.06 & 2.01 & -0.85 & -1.31 \\
\hline
\end{tabular}

The symbols ${ }^{* *}$ and ${ }^{*}$ indicate significant trends at $\alpha \leq 0.01$ and 0.05 , respectively.

TABle 3: Trends of changes in the annual minimum and maximum temperatures of weather stations in Southwest Ethiopia.

\begin{tabular}{lcccc}
\hline \multirow{2}{*}{ Station name } & \multicolumn{2}{c}{ Annual $T_{\max }$} & \multicolumn{2}{c}{ Annual $T_{\min }$} \\
& $Z$ & Sens' slope & $Z$ & Sens' slope \\
\hline Arfidee & $1.47^{* *}$ & 0.010 & $1.37^{* *}$ & 0.0102 \\
Demeka & $1.96^{*}$ & 0.016 & 0.02 & 0.0015 \\
Erbore & 1.37 & 0.009 & $2.64^{* *}$ & 0.0302 \\
Geto & $1.34^{* *}$ & 0.010 & $2.3^{*}$ & 0.0134 \\
Gazer & $2.24^{*}$ & 0.014 & $4.45^{* * *}$ & 0.0372 \\
Gidole & $2.95^{* *}$ & 0.041 & $1.35^{* *}$ & 0.0178 \\
Jinka & $3.42^{* *}$ & 0.041 & $2.3^{*}$ & 0.0228 \\
Keyafer & $2.58^{* *}$ & 0.008 & $2.12^{*}$ & 0.029 \\
Konso & $2.52^{* * *}$ & 0.036 & $1.75^{* *}$ & 0.026 \\
Omorate & $1.87^{* * *}$ & 0.022 & $3.52^{* * *}$ & 0.0275 \\
Basketo & $1.37^{* * *}$ & 0.016 & $1.59^{* *}$ & 0.0075 \\
Beto & $1.40^{* *}$ & 0.022 & $1.75^{* * *}$ & 0.0077 \\
\hline
\end{tabular}

The symbols ${ }^{* * *},{ }^{* *}$, and ${ }^{*}$ indicate significant trends at $\alpha \leq 0.001,0.01$, and 0.05 , respectively.

Scarcity of water for human and livestock use imposed a higher burden on us for searching the water in distant places.
TABLE 4: Farmers' perceptions of climate change over the thirty years (1983 to 2016).

\begin{tabular}{lcccc}
\hline Parameters & South Ari & Konso & $\chi^{2}$ & $P$ value \\
\hline Climate change & & & 1.67 & 0.45 \\
$\quad$ Perceived (\%) & 94.11 & 95.00 & & \\
$\quad$ Not perceived (\%) & 5.88 & 5.00 & & \\
Belg rainfall & & & & \\
$\quad$ Increased (\%) & 5.88 & 10.00 & 13.27 & 0.35 \\
Decreased (\%) & 88.2 & 87.5 & & \\
Not changed (\%) & 2.94 & - & & \\
I do not know (\%) & 2.94 & 2.5 & & \\
Autumn rainfall & & & & \\
Increased (\%) & 5.9 & 17.5 & 4.56 & 0.06 \\
Decreased (\%) & 94.1 & 82.5 & & \\
Not changed (\%) & 0.0 & 0.0 & & \\
I do not know (\%) & 0.0 & 0.0 & & \\
Temperature & & & & \\
Increased (\%) & 85.29 & 95.0 & 8.28 & 0.23 \\
Decreased (\%) & 11.79 & 0.0 & & \\
Not changed (\%) & 2.94 & 5.0 & & \\
I do not know (\%) & 0.0 & 0.0 & & \\
\hline
\end{tabular}

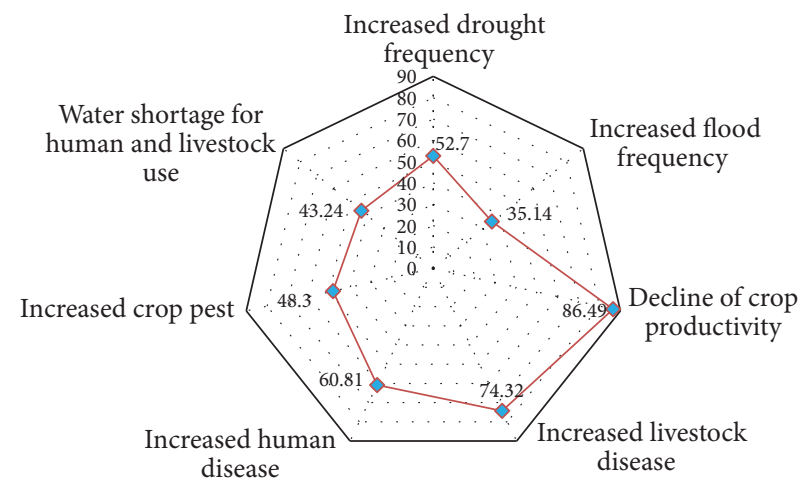

Figure 6: Perceived impacts of climate change by respondent farmers (\%) in Southwest Ethiopia.

Supporting the farmers' view on climate change and its impact, key informant interview participants also disclosed their observations as follows. 
The temperature and rainfall of our area have been changing. The rainfall received during the crop growing period was decreased that influenced the yield of crops. Similarly, the temperature was increasing from time to time. Population size has been increasing and posed pressure on natural resources especially cultivating land. Deforestation is practiced by people to alleviate the shortage of cropland that aggravated the effects of changes on temperature and rainfall. Farmers in the midland and high land area are producing crops that were produced in the low land area previously due to the change in rainfall and temperature. In addition, diseases like malaria occurred more frequently in different areas as compared to earlier periods. So, farmers are facing challenges in relation to climate change.

3.4. Farmers' Adaptation Responses to Impacts of Climate Change. During the survey study, locally adopted strategies by farmers to combat the impact of climate change were explored. Soil and water conservation practices $(66.21 \%)$ and crop diversification (62.16\%) were the most widely used adaptation strategies in the study area (Figure 7). Additionally, modifying planting date $(42.56 \%)$, agroforestry practices (35.13\%), use of drought-tolerant varieties $(33.95 \%)$, growing early maturing crops $(27.03 \%)$, and livelihood diversification (25.42\%) were other adaptation practices used by the farmers in their rank of adoption in the study area.

\section{Discussion}

4.1. Spatial Distribution and Variability of Rainfall and Temperature. The spatial distribution of annual and seasonal rainfall showed very high variation $(>31 \%)$ across the study area except for Spring rainfall for which moderate variability $(25.5 \%)$ was observed. The northern parts of the region received higher rainfall and experienced lower temperatures than the rest over the past three decades. Conversely, the southern parts of the region experienced higher annual maximum and minimum temperatures than the northern parts. Such high divergence of rainfall distribution might be attributed to the prevailing topographic differences in the region that ranged from 341 to 3399 m.a.s.l. The area with lower (Southern parts) and higher elevation (central and northern parts) experienced relatively lower and higher rainfall, respectively.Viste [49] and Tesfamariam et al. [50] reported that spatial variability of rainfall coincides with the profound effect of topography divergence across regions by creating numerous microclimates having different amounts of rainfall. Supporting this idea, Gummadi et al. [51] and Birara et al. [15] reported that stations in close proximity to mountainous topography and higher elevations receive higher rainfall than stations found in lower elevations. Exploring the spatial distribution of rainfall and temperature is important for determining the suitability of different areas for the production of different crops based on their environmental requirement. Furthermore, such information generated on a spatial basis could be used by

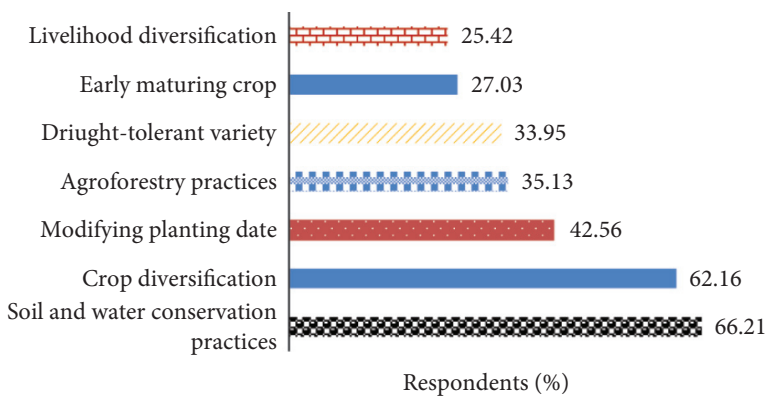

FIgURE 7: Adaptation strategies used by farmers in Southwest Ethiopia.

agricultural experts and policymakers to develop interventions based on the climatic conditions of different locations $[50,51]$.

4.2. Temporal Trends of Rainfall and Temperature. The region experienced inconsistent and statistically nonsignificant trends of annual and seasonal rainfall. Upward and downward trends were observed in different parts of the region. In line with this result, different reports showed the absence of clear trends in rainfall within and across regions in Ethiopia [23, 52-55]. The effect of topography, data sources, and its quality might be some of the reasons for such results [14]. The declining trends of rainfall on an annual and seasonal basis might have negative implications for rainfed agriculture [51]. Under such circumstances shifting of crop types which mature early and have better water use efficiency, crop diversification and small-scale irrigation practices are important interventions. On the other hand, the positive trends observed on annual and seasonal rainfall might not show a positive signal for agricultural practices since an increasing trend of rainfall would not necessarily have good distribution especially during the crop growing season. In this context, Hundera et al. [56] reported that though the rainfall had positive trends in different regions of Ethiopia, the annual and seasonal variability is very high and poses risks to agricultural production. Temporal trend analysis should be further supported by variability analysis to have good insight especially for agricultural activities [12].

Significant positive trends were detected on annual maximum and minimum temperatures. In agreement with this result, warming trends in maximum and minimum temperatures were reported by different authors for different regions of Ethiopia [55, 57, 58]. The increase of maximum and minimum temperatures of the region by 0.021 and $0.019^{\circ} \mathrm{C}$ per year, by 0.24 and $0.22^{\circ} \mathrm{C}$ per decade, and by 0.71 and $0.69^{\circ} \mathrm{C}$ over the last 34 years, respectively, was close to the reported values for different regions of Ethiopia. For instance, Esayas et al. [18] reported an increase of the maximum temperature by $0.02^{\circ} \mathrm{C}$ per year and $0.64^{\circ} \mathrm{C}$ over the period 1983 to 2014 for the low land area of Southern Ethiopia. In addition, Mengistu et al. [14] found an increasing trend of annual maximum temperature by $0.15^{\circ} \mathrm{C}$ per decade in the Upper Nile Basin. Similarly, Ademe et al. [53] reported that the annual minimum temperature of 
western Ethiopia showed an increasing trend ranging from 0.18 to $0.38^{\circ} \mathrm{C}$ per decade for the period 1983 to 2016 . Likewise, the trends of annual minimum temperature were in harmony with the experience of different regions of Ethiopia. Accordingly, a warming trend of the minimum temperature of Ethiopia by $0.37^{\circ} \mathrm{C}$ over the period 1951 to 2006 was observed [8]. Rising temperature has direct and indirect threats on people's life such as increased human and livestock disease, reduced productivity of crops and livestock, and increased water scarcity, particularly in the tropics. Moreover, it accelerates environmental degradation and food insecurity [59]. In such a situation, measures must be taken to counteract the effects associated with increasing temperature.

\subsection{Farmers' Perception of Climate Change, Its Impact, and} Their Adaptation Strategies. The majority of the respondent farmers perceived that there had been a decrease in annual and seasonal rainfall and an increase in temperature. This indicated that farmers were in a good position of understanding the changes in the climate of their locality. In addition, a statistically nonsignificant difference between farmers of South Ari and Konso on their perceptions of climate change, seasonal rainfall, and temperature indicated their similar level of understanding of changes in the local environmental conditions. In agreement with this result, other reports in different parts of Ethiopia indicated that farmers' understanding of climate change has been improved $[18,56]$. Furthermore, the farmers surveyed reported that they face risks as a result of climate change, such as increased drought and flood frequency, increased crop pest infestations, a decline in crop productivity, increased human and livestock disease, and water scarcity for humans and livestock. This showed that the areas were vulnerable to the impacts of climate change that influenced the livelihood of farmers directly and indirectly. In line with this result, earlier studies reported that farmers in different parts of Ethiopia faced similar risks with various degrees of severity $[60,61]$.

In response to the risks associated with the changing climate, farmers in Konso and South Omo used adaptation strategies such as soil and water conservation practices, crop diversification, modifying planting dates, agroforestry practices, use of drought-tolerant varieties, growing early maturing crops, and livelihood diversification. From these adaptation options, in particular soil and water conservation practices such as terrace, contour plowing, crop rotation, and crop diversification like intercropping have been adopted by smallholder farmers in the area. The area, especially Konso, is well known for its soil and water conservation practices, and it has become the culture of the community [16]. Moreover, the growth of multiple crops especially by intercropping was another common practice in the area. Despite those adaptation strategies found in the area, they had lower adoption and only small numbers of farmers were familiarized with these activities. This indicated that though farmers in the study area had good perceptions of climate change and its impact, they had weak adaptive capacity. In line with this, Darabant et al. [27] and
Bekele et al. [61] reported that though farmers' awareness of climate change had been improved through time, the level of adoption of different adaptation strategies to offset the negative impact of climate change is still low and external supports have to be provided. Furthermore, poverty, food insecurity, natural resources' degradation, high population growth, and poor social services pose multiple stresses on smallholder farmers and planned adaptation has to be implemented to strengthen the weak adaptive capacity of those people [62].

\subsection{Farmers' Perceptions of Climate Change Correspondence} with Climate Trend Analysis. The level of farmers' perceptions of the ongoing phenomena of climate change was in line with the result of climate data analysis. Farmers who participated in the in-depth interview and focus group discussion noted that they experienced the changing climate through its impact on their livelihood activities. Similarly, the analysis of climate data indicated the increasing annual maximum and minimum temperatures. Regarding precipitation, farmers in Konso and South Omo perceived that the rainfall was decreased and they faced different risks associated with scarcity of water such as low productivity of crop and livestock, total failure of crop stand, and food insecurity. On the contrary, clear trends of rainfall were not observed from the analysis of long-term data. Furthermore, Autumn rainfall was perceived as decreased while metrological data analysis showed increasing trends of rainfall during this season over the period 1983 to 2016 . Such discrepancies on trends of rainfall and farmers' perception might be attributed to two conditions. First, the analysis of climate data can not entirely explain farmers' perception of climate change since climate data records capture average conditions at a large spatial scale [63]. Second, farmers perceived climate change based on rainfall intensity and distribution, frequency, and magnitudes of extreme events on a narrow spatial scale [64]. Moreover, Esayas et al. [18] explained that farmers' perception of climate change is further influenced by social, economic, demographic, and institutional factors. Thus, for better planning and adoption of strategies to cope with the impacts of climate change, exploring farmers' perceptions linked with the analysis of climate data at a local level is vital $[25,27]$.

\section{Conclusion}

Spatial analysis of long-term climate data revealed that there was high variability of rainfall and temperature across the region. The northern region received higher annual and seasonal rainfall compared to the rest parts while annual maximum and minimum temperatures were lower for the northern parts of the region. Annual maximum and minimum temperatures of the region showed increasing trends over the period 1983 to 2016. Similarly, the time series analysis of rainfall showed that the region experienced inconsistent and statistically nonsignificant trends for the same period. The results of the household-level survey indicated that farmers in the region had good awareness of the 
phenomena of climate change and its impact. In addition, statistically nonsignificant differences were observed between farmers in South Ari and Konso on their perceptions of climate change. The perceptions of farmers on climate change were aligned with the result of climate data analysis except for Autumn rainfall. Furthermore, they had different adaptation options to counteract the impacts of climate change though only a small number of farmers were practicing most of the strategies. Overall, it can be concluded that though farmers in the region perceived climate change and its impacts, there were limitations on using different appropriate and diverse adaptation strategies. Thus, further study should be conducted to explore the factors hindering the adoption of strategies that would be helpful to offset the impact of climate change. Furthermore, governmental and nongovernmental support in terms of introducing and popularizing appropriate adaptation strategies should be provided to strengthen the adaptive capacity of farmers.

\section{Data Availability}

All the raw and processed data are available from the corresponding author upon request. However, permission is required from the National Meteorological Agency of Ethiopia to provide raw rainfall and temperature data.

\section{Conflicts of Interest}

The authors declare that there are no conflicts of interest regarding the publication of this article.

\section{Acknowledgments}

The work is an output of a Ph.D. scholarship at the Hawassa University, in the framework of the German-Ethiopian SDG Graduate School "Climate Change Effects on Food Security (CLIFOOD)" between the Food Security Center, University of Hohenheim (Germany). and the Hawassa University (Ethiopia), supported by the DAAD with funds from the Federal Ministry for Economic Cooperation and Development (BMZ). The authors acknowledge the National Meteorological Agency of Ethiopia for the provision of rainfall and temperature data.

\section{Supplementary Materials}

The supplementary material describes the sociodemography of the household head who participated in the interview. (Supplementary Materials)

\section{References}

[1] C. Clarke, S. Shackleton, and M. Powell, "Climate change perceptions, drought responses and views on carbon farming amongst commercial livestock and game farmers in the semiarid great fish river valley, eastern Cape province, South Africa," African Journal of Range \& Forage Science, vol. 29, no. 1, pp. 13-23, 2012.

[2] NOAA, Global Climate Report-Annual 2020, National Centers for Environmental Information, Washington, DC, USA, 2020, https://www.ncdc.noaa.gov/sotc/global/202013.
[3] A. Cosbey, Developing Country Interests in Climate Change Action and the Implications for a Post-2012 Climate Change Regime, United Nations, New York, NY, USA, 2009.

[4] World Bank, World Development Report. Development and Climate Change, The World Bank, Washington, DC, USA, 2010.

[5] IPCC, Climate Change 2001, the Scientific Basis, Cambridge University Press, Cambridge, UK, 2001.

[6] I. Niang, O. C. Ruppel, M. A. Abdrabo et al., "Africa," in Climate Change 2014: Impacts, Adaptation, and Vulnerability. Part B: Regional Aspects. Contribution of Working Group II to the Fifth Assessment Report of the Intergovernmental Panel on Climate Change, V. R. Barros, C. B. Field, D. J. Dokken et al., Eds., Cambridge University Press, Cambridge, UK, 2014.

[7] B. Shiferaw, K. Tesfaye, M. Kassie, T. Abate, B. M. Prasanna, and A. Menkir, "Managing vulnerability to drought and enhancing livelihood resilience in sub-Saharan Africa: technological, institutional and policy options," Weather and Climate Extremes, vol. 3, pp. 67-79, 2014.

[8] NMA, "Climate change national adaptation program of action (NAPA) of Ethiopia," Federal Democratic Republic of Ethiopia Ministry of Water Resources, National Meteorological Agency, Addis Ababa, Ethiopia, 2007.

[9] M. Keller, "Climate risks and development projects, assessment report for a community-level project in Guduru, Oromiya, Ethiopia, bread for all," 2009, https://www.iisd.org/cristaltool/ documents/BFA-Ethiopia-Assessment-Report-Eng.pdf.

[10] A. Amsalu, W. Negatu, and N. C. Trujillo, "Climate finance in Ethiopia,” 2014, https://www.odi.org/sites/odi.org.uk/files/ odi-assets/publications-opinion-files/8995.pdf.

[11] M. R. Jury and C. Funk, "Climatic trends over Ethiopia: regional signals and drivers," International Journal of Climatology, vol. 33, no. 8, pp. 1924-1935, 2013.

[12] A. Asfaw, B. Simane, A. Hassen, and A. Bantider, "Variability and time series trend analysis of rainfall and temperature in northcentral Ethiopia: a case study in Woleka sub-basin," Weather and Climate Extremes, vol. 19, pp. 29-41, 2018.

[13] F. Benti and M. Abara, "Trend analyses of temperature and rainfall and their response to global $\mathrm{CO}_{2}$ emission in Masha, southern Ethiopia," Caraka Tani: Journal of Sustainable Agriculture, vol. 34, no. 1, pp. 67-75, 2019.

[14] D. Mengistu, W. Bewket, and R. Lal, "Recent spatiotemporal temperature and rainfall variability and trends over the upper Blue Nile river basin, Ethiopia," International Journal of Climatology, vol. 34, no. 7, pp. 2278-2292, 2014.

[15] H. Birara, R. P. Pandey, and S. K. Mishra, "Trend and variability analysis of rainfall and temperature in the Tana basin region, Ethiopia," Journal of Water and Climate Change, vol. 9, no. 3, pp. 555-569, 2018.

[16] K. Araro, S. A. Legesse, and D. T. Meshesha, "Climate change and variability impacts on rural livelihoods and adaptation strategies in southern Ethiopia," Earth Systems and Environment, vol. 4, no. 1, pp. 15-26, 2019.

[17] D. Ayalew, K. Tesfaye, G. Mamo, B. Yitaferu, and W. Bayu, "Variability of rainfall and its current trend in Amhara region, Ethiopia," African Journal of Agricultural Research, vol. 7, no. 10, pp. 1475-1486, 2012.

[18] B. Esayas, B. Simane, E. Teferi, V. Ongoma, and N. Tefera, "Climate variability and farmers' perception in Southern Ethiopia," Advances in Meteorology, vol. 2019, Article ID 7341465, 19 pages, 2019.

[19] B. D. Enyew and R. Hutjis, "Climate change impact and adaptation in south Omo zone, Ethiopia," Journal of Geology and Geophysics, vol. 4, p. 208, 2015. 
[20] D. O. Gemeda, "Climate change variability analysis in and around Jinka, southern Ethiopia. With special emphasis on temperature and rainfall," Journal of Agricultural Sciences-Sri Lanka, vol. 14, no. 3, pp. 145-153, 2019.

[21] T. Teyso and A. Anjulo, "Spatio-temporal variability and trends of rainfall and temperature over Gamo Gofa zone, Ethiopia," Journal of Scientific Research and Reports, vol. 12, no. 2, pp. 1-11, 2016.

[22] A. Gebremichael, S. Quraishi, and G. Mamo, "Analysis of seasonal rainfall variability for agricultural water resource management in southern region, Ethiopia," Journal of Natural Sciences Research, vol. 4, p. 11, 2014.

[23] B. T. Kassie, H. Hengsdijk, R. Rötter, H. Kahiluoto, S. Asseng, and M. Van Ittersum, "Adapting to climate variability and change: experiences from cereal-based farming in the central rift and kobo valleys, Ethiopia," Environmental Management, vol. 52, no. 5, pp. 1115-1131, 2013.

[24] M. Y. Mkonda, X. He, and E. S. Festin, "Comparing smallholder farmers' perception of climate change with meteorological data: experience from seven agroecological zones of Tanzania," Weather, Climate, and Society, vol. 10, no. 3, pp. 435-452, 2018.

[25] M. Niles and N. D. Mueller, "Farmer perceptions of climate change: associations with observed temperature and precipitation trends, irrigation, and climate beliefs," Global Environmental Change, vol. 39, pp. 133-142, 2016.

[26] A. Ayanlade, M. Radeny, and J. F. Morton, "Comparing smallholder farmers' perception of climate change with meteorological data: a case study from southwestern Nigeria," Weather and Climate Extremes, vol. 15, pp. 24-33, 2017.

[27] A. Darabant, B. Habermann, K. Sisay et al., "Farmers' perceptions and matching climate records jointly explain adaptation responses in four communities around Lake Tana, Ethiopia," Climatic Change, vol. 163, no. 1, pp. 481-497, 2020.

[28] A. Mekasha and A. J. Duncan, "Trends in daily observed temperature and precipitation extremes over three Ethiopian eco-environments," International Journal of Climatology, vol. 34, no. 6, pp. 1990-1999, 2014.

[29] A. Berhane, G. Hadgu, W. Worku, and B. Abrha, "Trends in extreme temperature and rainfall indices in the semi-arid areas of Western Tigray, Ethiopia," Environmental System Research, vol. 9, no. 3, pp. 1-20, 2020.

[30] Y. A. Tessema, C. S. Aweke, and G. S. Endris, "Understanding the process of adaptation to climate change by small-holder farmers: the case of east Hararghe Zone, Ethiopia," Agricultural and Food Economics, vol. 1, no. 1, p. 13, 2013.

[31] A. Yimam and Y. Mohammed, "Local perceptions and adaptations to climate change and variability: evidences from southern Ethiopia," International Journal of Environmental Sciences, vol. 1, no. 2, pp. 1-23, 2016.

[32] G. Gebrekiros, A. Araya, and T. Yemane, "Modeling impact of climate change and variability on sorghum production in southern zone of Tigray, Ethiopia," Journal of Earth Science and Climatic Change, vol. 7, p. 322, 2016.

[33] BoFED, Annual Statistical Abstract, Southern Nations, Nationalities and Peoples' Regional State Bureau of Finance and Economic Development, Hawassa, Ethiopia, 2012.

[34] A. Habte, W. Worku, S. Gayler, D. Ayalew, and G. Mamo, "Model-based yield gap analysis and constraints of rainfed sorghum production in southwest Ethiopia," The Journal of Agricultural Science, vol. 158, pp. 855-869, 2021.

[35] B. Esayas, B. Simane, E. Teferi, V. Ongoma, and N. Tefera, "Trends in extreme climate events over three agroecological zones of southern Ethiopia," Advances in Meteorology, vol. 2018, Article ID 7354157, 17 pages, 2018.

[36] X. Zhang and F. Yang, RClimDex (1.0) User Manual. Climate Research Branch, Environment Canada, Ontario, Canada, 2004.

[37] T. Yamane, Statistics, an Introductory Analysis, Harper and Row Inc., New York, NY, USA, 2nd edition, 1967.

[38] D. Duhan and A. Pandey, "Statistical analysis of long term spatial and temporal trends of precipitation during 1901-2002 at Madhya Pradesh, India," Atmospheric Research, vol. 122, pp. 136-149, 2013.

[39] W. Hare, Assessment of Knowledge on Impacts of Climate Change, Contribution to the Specification of Art. 2 of the UNFCCC, WBGU, Berlin, Germany, 2003.

[40] S. Yue, P. Pilon, B. Phinney, and G. Cavadias, "The influence of autocorrelation on the ability to detect trend in hydrological series," Hydrological Processes, vol. 16, no. 9, pp. 1807-1829, 2002.

[41] K. Kafadar, J. R. Koehler, W. N. Venables, and B. D. Ripley, "Modern applied statistics with S-plus," The American Statistician, vol. 53, pp. 86-87, 2006.

[42] S. Alashan, "Combination of modified Mann-Kendall method and Şen innovative trend analysis," Engineering Reports, vol. 2, no. 3, 2020.

[43] R Core Team, R: A Language and Environment for Statistical Computing, R Foundation for Statistical Computing, Vienna, Austria, 2018, https://www.Rproject.org/.

[44] M. G. Kendall, "A new measure of rank correlation," Biometrika, vol. 30, no. 1-2, pp. 81-93, 1955.

[45] H. B. Mann, "Nonparametric tests against trend," Econometrica, vol. 13, no. 3, pp. 245-259, 1945.

[46] P. K. Sen, "Estimates of the regression coefficient based on Kendall's tau," Journal of the American Statistical Association, vol. 63, no. 324, pp. 1379-1389, 1968.

[47] D. R. Helsel and R. M. Hirsch, Statistical Methods in Water Resources, United States Geological Survey, Reston, VA, USA, 2002.

[48] D. K. Karpouzos, S. Kavalieratou, and C. Babajimopoulos, "Trend analysis of precipitation data in Pieria region (Greece)," European Water, vol. 30, pp. 31-40, 2010.

[49] E. Viste, Moisture transport and precipitation in Ethiopia, Ph.D. Thesis, University of Bergen, Bergen, Norway, 2012.

[50] B. G. Tesfamariam, B. Gessesse, and F. Melgani, "Characterizing the spatiotemporal distribution of meteorological drought as a response to climate variability: the case of rift valley lakes basin of Ethiopia," Weather and Climate Extremes, vol. 26, Article ID 100237, 2019.

[51] S. Gummadi, K. P. Rao, J. Seid et al., "Spatio-temporal variability and trends of precipitation and extreme rainfall events in Ethiopia in 1980-2010," Theoretical and Applied Climatology, vol. 134, no. 3-4, pp. 1315-1328, 2017.

[52] A. Alemayehu, M. Maru, W. Bewket, and M. Assen, "Spatiotemporal variability and trends in rainfall and temperature in Alwero watershed, western Ethiopia," Environmental Systems Research, vol. 9, no. 1, p. 22, 2020.

[53] E. Viste, D. Korecha, and A. Sorteberg, "Recent drought and precipitation tendencies in Ethiopia," Theoretical and Applied Climatology, vol. 112, no. 3-4, pp. 535-551, 2012.

[54] A. Alemayehu and W. Bewket, "Local spatiotemporal variability and trends in rainfall and temperature in the central highlands of Ethiopia," Geografiska Annaler: Series A, Physical Geography, vol. 99, no. 2, pp. 85-101, 2017.

[55] D. Ademe, B. F. Ziatchik, K. Tesfaye, B. Simane, G. Alemayehu, and E. Adgo, "Climate trends and variability at 
adaptation scale: patterns and perceptions in an agricultural region of the Ethiopian Highlands," Weather and Climate Extremes, vol. 29, Article ID 100263, 2020.

[56] H. Hundera, S. Mpandeli, and A. Bantider, "Smallholder farmers' awareness and perceptions of climate change in Adama district, central rift valley of Ethiopia," Weather and Climate Extremes, vol. 26, Article ID 100230, 2019.

[57] G. Gebremeskel Haile, Q. Tang, S. Sun, Z. Huang, X. Zhang, and X. Liu, "Droughts in East Africa: causes, impacts and resilience," Earth-Science Reviews, vol. 193, pp. 146-161, 2019.

[58] T. Matewos and T. Tefera, "Local level rainfall and temperature variability in drought-prone districts of rural Sidama, central rift valley region of Ethiopia," Physical Geography, vol. 41, no. 1, pp. 36-53, 2020.

[59] T. Das, M. Hajong, D. Majumdar, R. K. Tombisana Devi, and T. Rajesh, "Climate change and livestock: impacts, adaptation, and mitigation," Journal of Agriculture, vol. 14, no. 2, pp. 200-209, 2016.

[60] T. Matewos, "Climate change-induced impacts on smallholder farmers in selected districts of Sidama, Southern Ethiopia," Climate, vol. 7, no. 5, p. 70, 2019.

[61] M. Bekele, M. Bezabih, H. Elias et al., "Building resilience to climate change in Ethiopia, what do we know so far? 6-212020," Development Economics Research Group, Copenhagen University, Copenhagen, Denmark, 2020.

[62] FAO, Strengthening Capacity for Climate Change Adaptation in the Agriculture Sector in Ethiopia Proceedings from National Workshop, FAO, Nazreth, Ethiopia, 2011.

[63] T. Deressa, R. M. Hassan, and C. Ringler, "Perception of and adaptation to climate change by farmers in the Nile basin of Ethiopia," Journal of Agricultural Science, vol. 149, no. 1, pp. 23-31, 2011.

[64] G. P. Marchildon, E. Wheaton, A. J. Fletcher, and J. Vanstone, "Extreme drought and excessive moisture conditions in two Canadian watersheds: comparing the perception of farmers and ranchers with the scientific record," Natural Hazards, vol. 82, no. 1, pp. 245-266, 2016. 